\title{
Sobre el derecho constitucional y su fundamentos (segunda parte). Rechtsstaat y teoría de la Constitución en el período de entreguerras ${ }^{1}$
}

\author{
On the constitutional law and its foundations \\ (part two). Rechtsstaat and theory of the \\ Constitution in the interwar period
}

Sobre o direito constitucional e seus fundamentos (parte dois). Rechtsstaat e teoria da Constituição no periodo entre guerras

Sur le droit constitutionnel et ses fondements (partie 2). Autorité de la loi et théorie de la Constitution dans l'Entre-deux-guerres 论宪法及其基础(2). 宪法与宪政的历史基础

Miguel Revenga Sánchez ${ }^{2}$ | Universidad de Cádiz, España

Revista Derechos en Acción ISSN 2525-1678/ e-ISSN 2525-1686 Año 4/Nº 13, Primavera 2019 (21 septiembre a 20 diciembre), 29-73 DOI: https://doi.org/10.24215/25251678e330 ORCID: https://orcid.org/ 0000-0002-7807-6684 Recibido: 01/07/2019 Aprobado: 01/08/2019

Resumen: En un trabajo sobre los fundamentos del derecho constitucional, rescatando las bases históricas de la constitución y el constitucionalismo el autor plantea que en la enseñanza y estudio de la materia el constitucionalista debe esforzarse por atraer la atención del alumno acerca los siguientes extremos; a ) Cuál es el significado de la

\footnotetext{
1 El presente trabajo es el segundo de una serie de tres que aparecen publicados con carácter sucesivo en los siguientes números 12, el actual y el 14, respectivamente, de REDEA.

2 Catedrático de Derecho Constitucional en la Universidad de Cádiz.

E-mail: miguel.revenga@uca.es
} 
Constitución como norma política en la que se encuentra el agregado de ideas y concepciones que permite fundamentar un orden de convivencia democrática. b) Qué es lo que diferencia, formal y materialmente, a la Constitución del resto de las normas que integran el ordenamiento jurídico y, last but not least, y c) Cuáles son las técnicas mediante las cuales se persigue el influjo que la Constitución debería ejercer sobre el ordenamiento jurídico en su dinámica de funcionamiento efectivo.

Palabras clave: Constitución. Derecho Constitucional. Enseñanza.

Abstract: In a work about the foundations of constitutional law, rescuing the historical basis of the constitution and constitutionalism, the author states that in the teaching and study of the subject, the Constitutionalist must make an effort to attract the attention of the student on following: a) What is the meaning of the Constitution as a political norm in which the aggregate of ideas and conceptions of an order of democratic coexistence are present. b) What differentiates, formally and materially, the Constitution from the rest of the norms that integrate the legal system and, last but not least, c) What are the techniques by which the influence that the Constitution should exert is pursued on the legal system, in its dynamics of effective functioning.

Keywords: Constitution. Constitutional right. Teaching.

Resumo: Em um trabalho sobre os fundamentos do direito constitucional, resgatando as bases históricas da constituição e o constitucionalismo, 0 autor afirma que no ensino e estudo da matéria, o constitucionalista deve se esforçar para atrair a atenção do aluno sobre os seguintes extremos: a) Qual é o significado da Constituição como norma política na que está 0 agregado de ideias e concepções que permitem basear uma ordem de convivência democrática. b) 0 que diferencia, formal e materialmente, a Constituição do resto das normas que integram 0 sistema legal e, last but not least, c) Quais são as técnicas pelas quais o influxo que a Constituição deve exercer sobre o sistema legal em sua dinâmica de funcionamento efetivo é perseguido?

Palavras-chave: Constituição Direito constitucional. Ensino.

Résumé: Dans cet article sur les fondements du droit constitutionnel, qui sauvegarde les bases historiques de la constitution et du constitutionnalisme, l'auteur considère que, dans l'enseignement et l'étude de 
cette matière, le constitutionnaliste doit s'efforcer d'attirer l'attention de l'élève sur les différents points suivants; a) que signifie la Constitution en tant que norme politique regroupant un ensemble d'idées et de conceptions qui permettent de fonder un ordre de coexistence démocratique? b) qu'est-ce qui différencie, formellement et concrètement, la Constitution du reste des normes qui intègrent le système juridique et, last but not least, c) Quelles sont les techniques à travers lesquelles se poursuit l'influence que la Constitution devrait exercer sur le système juridique dans sa dynamique de fonctionnement effective.

Mot-clés: Constitution Droit constitutionnel. Enseignement.

摘要: 在一部关于宪法基础的工作中, 拯救宪法和宪政的历史基础, 作者指出, 在该学科的教学和研究中, 宪政主义者必须努力吸引学 生关注以下极端; a) 宪法作为一种政治规范的含义是什么, 其中是 允许建立民主共存秩序的思想和概念的总和。 b ) “宪法”与其他整 合法律体系的规范, 最后但并非最不重要的, 以及c） “宪法”应施加 的影响的技术有何区别, 正式和实质上有何区别关于法律制度的有 效运作动态。

关键字: 关键字: 政治宪法, 宪法, 教学

\section{Estado de Derecho, declive de la Constitución y Teoría del Estado}

Pocos autores de libros jurídicos pueden presumir de haber iniciado sus libros con una frase que se haya convertido en célebre. Uno de ellos es, sin duda, Elías Díaz, cuyo Estado de Derecho y Sociedad democrática arranca con la famosa sentencia apodíctica "no todo Estado es Estado de Derecho".

Las primeras palabras del segundo párrafo del libro no son menos significativas:

"Cabe adoptar como punto de partida la siguiente tesis: el Estado de Derecho es el Estado sometido al Derecho, o mejor el Estado cuyo poder y actividad vienen regulados y controlados por la ley; el Estado de Derecho consiste así fundamentalmente 
en el 'imperio de la ley': Derecho y ley entendidos en este contexto como expresión de la 'voluntad general"'3.

$\mathrm{Al}$ cabo de treinta años largos, lo que sorprendería a cualquier lector no avisado de las circunstancias políticas bajo las cuales se redactó el libro, es la falta de cualquier referencia a la Constitución, así como el arcaísmo de la equiparación del Derecho y de la ley a la 'voluntad general'. Bastaría con sustituir "Derecho" por "Constitución", y "voluntad general" por "voluntad soberana del pueblo", para que las cosas sonaran mucho más actuales.

En el eficaz alegato de Elías Díaz, éste contrapone el Estado de Derecho al Estado totalitario (Capítulo II: "Fascismo y Estado totalitario"), y los tipos de Estado "social de Derecho" y "democrático de Derecho" aparecen como formas superadoras del primero (Capítulos III y IV, respectivamente; este último con su enfático arranque "El análisis y comprensión de las insuficiencias y contradicciones del sistema económico y del sistema ideológico derivado del neocapitalismo marca, puede decirse, el sentido de la superación del Estado social de Derecho : el paso al socialismo será así paralelamente el paso al Estado democrático de Derecho", (Estado de Derecho y Sociedad democrática, p. 89).

El apéndice bibliográfico del libro, dividido en dos Apartados, el primero propiamente de "bibliografía sobre el Estado de Derecho", y el segundo, dividido por voces, bajo la rúbrica "otras referencias bibliográficas", es muy ilustrativo para comprobar la escasa atención que las literaturas académicas germana, italiana y francesa (y por supuesto también la española) prestaban por entonces al valor de la Constitución como norma sustentadora de la democracia.

En el índice por voces no aparece el vocablo, y en el propiamente bibliográfico, con 127 entradas, las referencias se limitan (salvo error u omisión por mi parte) a un trabajo de Maurus,

\footnotetext{
3 Elías Díaz, Estado de Derecho y Sociedad Democrática, Madrid, Edicusa, 1966, p. 7. Y de imprescindible lectura complementaria resultan también los trabajos del propio Elías Díaz, agrupados en el libro Un itinerario intelectual. De filosofía jurídica y política, Madrid, Biblioteca Nueva, 2003
} 
de 1898, titulado - ironías de la historia -Der Moderne Verfassungsstaat als Rechtsstaat, a un par de estudios sobre la (a la sazón emergente) justicia constitucional (el de Leibholz, de 1954, Verfassungsgericchtsbarkeit in demokratischen Rechtsstaat, y el de Lucas Verdú, de 1957, "Problemática actual de la justicia constitucional y del examen de constitucionalidad de las leyes"), así como a un trabajo de Raúl Morodo, de 1962, que lleva por título "Constitución, legalidad, legitimidad"

Si algún interés tiene curiosear sobre tales minucias, no es para evocar un pasado en el que se hacía imprescindible explicar lo evidente, sino para confortarse con la constatación del impacto que en la cultura jurídica, y no sólo en la española, ha producido la vigencia de una Constitución genuinamente normativa. Una Constitución que, precisamente por serlo, resulta la única capaz de proclamar, permitiendo que se asienten, los valores propios de una sociedad democrática.

La expresión "Estado de Derecho" se nos aparece como algo imprecisa y, según algunos, hasta tautológica. En uno de sus últimos trabajos, Adolf Merkl denunciaba la ambigüedad de la fórmula, poniendo de relieve que la expresión podía significar cosas opuestas: a) un Estado que ejerce su poder por medio del Derecho, o bien, b) un Estado que no sólo domina mediante el Derecho, sino que también está dominado por el Derecho 5 .

Cosas tan opuestas que no hay, que yo sepa, monografía o estudio sobre el particular que no necesite realizar un esfuerzo

4 En las memorias de Raúl Morodo, Atando Cabos, Madrid, Taurus, 2001, pp. 99 y ss., éste evoca el clima intelectual - el del Seminario de Derecho Político de Salamanca - en el que se gestarán, bajo el influjo de Tierno Galván y Lucas Verdú (cuyo Estado liberal de derecho y Estado social de Derecho había aparecido en 1955) el trabajo mencionado en el texto, y el del propio Elías Díaz. Véase también el Escrito de Elías Díaz, “De un tiempo, de un país. Notas para una autobiografía intelectual", publicado originariamente en 1986, y ahora incluido en el libro citado en la nota anterior.

5 "Idee und Gestalt des Rechtsstates", en Festschrift für Hans Kelsen zum 90 Geburtsag, Viena, Deuticke, 1971, p. 126, citado en Massimo La Torre, “Derecho y conceptos de Derecho. Tendencias evolutivas desde una perspectiva europea", Revista del Centro de Estudios Constitucionales, 16 (1993), pp. 67 y ss. 
encaminado a esclarecer a qué nos referimos cuando hablamos de Estado de Derecho ${ }^{6}$.

En la formulación constitucional, y en el debate teórico, la "selva" del Estado de Derecho sólo se hace transitable gracias a la concatenación de adjetivos cualificadores: "republicano, democrático y social" en la Constitución alemana, "social y democrático" en la española.

Sobre los alumnos de nuestras Facultades de Derecho recae un aluvión de conceptos, que los docentes utilizamos a menudo de manera intercambiable y escasamente meditada. Si llegamos a alcanzar algún éxito, y siempre y cuando el arsenal conceptual de las distintas áreas de conocimiento no venga a enturbiar las cosas, cabe esperar que, al cabo de algunos meses, desemboquemos en ciertas "convenciones comunicativas" que sirvan para entendernos.

Podremos así dar por sentado que, cuando adjetivamos al Estado de Derecho como liberal, poniendo todo el énfasis del mundo en el adjetivo, estamos pensando en una forma de Estado que es constitucional, pero no democrático. Pasamos por alto que, obrando así, presentamos liberalismo y democracia en relación conflictiva, lo que en el (más bien improbable) supuesto de que el alumno siga de cerca el debate público, puede ser origen de no pocas confusiones. Si hablamos de Estado social (o de Estado del bienestar), locución esta última idónea también para suscitar nuevas perplejidades, estaremos de acuerdo en que nos referimos a una forma de Estado que sucede históricamente al Estado liberal. Que, a renglón seguido, seamos propensos a embarcaros en consideraciones sobre la crisis del Estado social, sin aclarar si ello supone el tránsito hacia formas nuevas, o bien la resurrección, cuando menos parcial, de formas periclitadas, es algo que, en este momento, podemos pasar por alto.

6 De referencia inexcusable es ahora el volumen coordinado por Pietro Costa y Danilo Zolo, Lo Stato di diritto. Storia, teoria, critica, Milán, Feltrinelli, 2002, con más de 25 trabajos de diferentes teóricos del Derecho, historiadores y constitucionalistas de distintos ámbitos culturales. Incluye un equilibrado "Saggio bibliografico" a cargo de Francesco Vertova. 
Tenemos, por tanto, un calificativo central, "de Derecho", y cuatro adjetivos, constitucional, democrático, liberal y social, que son repertorio suficiente para dar cuenta de una evolución. En ella lo constitucional permanece (aunque su importancia varía de un momento a otro), y lo demás va gravitando en torno a lo central hasta alcanzar una convergencia, en la que lo constitucional se convierte, por sus implicaciones, en el elemento hegemónico.

El resultado deseable sería, en suma, el asentamiento de una "convención comunicativa", en la que bastaría, para explicarlo todo, con invertir el título del libro de Maurus al que antes nos hemos referido: el moderno Estado de Derecho como Estado Constitucional (y, por ende, social y democrático).

La explicación de las razones por las que la fórmula "Estado de Derecho" pudo hacer fortuna, arrinconando el componente constitucional, hasta desembocar en el dilema, planteado en 1929 por Herman Heller, "Estado de Derecho o Dictadura" se corresponden exactamente con las apuntadas para referirnos a la incierta suerte del constitucionalismo europeo durante el siglo XIX ${ }^{7}$. En primer lugar está la congénita polisemia de la idea, una "discutibilidad esencial" a la que no se sustrae el Estado de Derecho, como concepto político que es al fin y al $\mathrm{cabo}^{8}$.

En un Estudio que cabe, en tal sentido, tildar de "reconstruccionista", Bartolomé Clavero constata que los conceptos de "autogobierno", "Estado de Derecho" y "regla de derecho" (Selfgovernment, Rechtsstaat y Rechtssatz) "son también inventos más que descubrimientos, artefactos culturales más performativos y

\footnotetext{
7 Herman Heller, "Estado de Derecho o Dictadura", en Escritos políticos, Madrid, Alianza, 1985, pp.283 y ss. El trabajo de Heller arranca, por cierto, con una llamada de atención sobre el éxito de la fórmula: "Hasta el desenlace de la Guerra Mundial el Estado de Derecho pertenecía en Europa al acervo común de ideas. Como reivindicación no era discutido ni aun allí donde, ya en un todo ya parcialmente, no se le había reconocido o llevado a la práctica".

8 Cfr., en general, Felix Oppenheim, Conceptos políticos. Una reconstrucción, Madrid, Tecnos, 1987, Cpt. IX, bajo el epígrafe "Defensa del reconstruccionismo".
} 
generadores, que intelectivos y analíticos"9. El trabajo toma como punto de arranque las palabras con las que Tomás y Valiente iniciara, en septiembre de 1995, una conferencia sobre "Independencia judicial y garantía de los derechos fundamentales":

"No hay dogmática sin historia. O no debería haberla, porque los conceptos y las instituciones no nacen en un vacío puro e intemporal, sino en lugar y fecha conocidos y a consecuencia de procesos históricos de los que arrastran una carga quizá invisible, pero condicionante".

El lugar y la fecha en los que la locución "Estado de derecho" entra en escena son conocidos: el trabajo de Robert von Mohl, aparecido en Tubinga, en 1832, con el título Die Polizeiwissenschaft nach den Grundsätzen des Rechtsstaates ${ }^{10}$. El pensamiento de Mohl puede sintetizarse en la visión de un ordenamiento de la vida del pueblo en la que cada ciudadano sea sostenido y ayudado en el ejercicio de su libertad. Como dicha libertad representa el más alto principio que el Estado debe respetar, éste no puede tener más que una función 'negativa'.

El contexto de la aparición en escena de la locución también es muy preciso: las (llamadas) Monarquías limitadas de los Estados germánicos, con vigencia de Principio Monárquico. Unos Estados donde subsisten extensas zonas de inmunidad en la actuación del Rey y su ejecutivo, precisamente, frente al Derecho ${ }^{11}$.

Así mismo está bien identificado el fundamento filosófico. Se trata del pensamiento de Kant, resumido en la famosa afirmación "cualquier acto es conforme al derecho cuando, por medio

\footnotetext{
9 Bartolomé Clavero, "Imperio de la ley y rule of law. tópica y léxico constitucionales", en Happy Constitution. Cultura y lengua constitucionales, Madrid, Trotta, 1997, pp. 181 y ss.

10 Cfr. Vincenzo Zangara, "Lo Stato di Diritto in evoluzione", Diritto e Società, 2 [1983], pp.193 y ss. También Danilo Zolo, "Teoria e Critica dello Stato di diritto", en el volumen colectivo citado más arriba.

11 El contexto político aparece magistralmente resumido en el trabajo de Francisco Sosa Wagner, Maestros alemanes del Derecho Público (I), Madrid, Marcial Pons, 2002, con Epígrafe específico dedicado a Von Mohl (“Donde se persigue al incansable trabajador Robert Von Mohl y se analiza su obra ambiciosa").
} 
del mismo, o según su máxima, la libertad de arbitrio de cada cual puede coexistir con la libertad de los otros, según una ley universal". El concepto kantiano de libertad como capacidad para decidirse a querer por uno mismo, y la distinción entre la esfera de la moralidad y la de la legalidad, serán determinantes para la configuración del Estado como una organización puramente jurídica, sin otra misión que la de posibilitar una convivencia ordenada entre los individuos.

Se ha podido así decir que "toda la ciencia del Derecho Público alemán tiene, en este aspecto, su origen en Kant, que ha enseñado a considerar como función esencial del Estado la regulación y la sanción del derecho, y como límite de la acción estatal esta misma regulación y esta misma sanción"12.

La codificación vendrá a ser el expediente técnico por virtud del cual se intenta salvaguardar la libertad civil del individuo contra las injerencias del poder político. El Código desplaza a la Constitución, empobrece el contenido de ésta y le asesta un golpe crucial a su originaria razón de ser. Y ello pese a la común matriz de ambos fenómenos, constitucionalizador y codificador, expresión ambos de un racionalismo jurídico que dará pronto sus frutos con la tecnificación de la ciencia jurídica, y la consiguiente "neutralización" política de sus cultivadores ${ }^{13}$.

Frente a la mutabilidad e incertidumbre de la Constitución, se trataba de resaltar la estabilidad y la certeza del Código, tal y como dijera Zeiller, el impulsor y factótum del Allgemeines Buergenliches Gesetzbuch austriaco de 1808: "es necesario separar la materia del Derecho Civil de la del Derecho Político, porque aquél representa el orden natural frente a un orden artificial y estatuido" 14 .

\footnotetext{
12 Guido de Ruggiero, Historia del Liberalismo europeo, Madrid, Pegaso, 1944, p. 172.

13 Remito, de nuevo, a Tarello, Storia della cultura giuridica moderna. I Assolutismo e codificazione del diritto, cit., "Introduzione", passim.

14 Cit. en Enrique Gómez Arboleya, "El racionalismo jurídico y los Códigos europeos", en la recopilación de trabajos de dicho autor, Estudios de teoría de la sociedad y del Estado, cit., p. 542.
} 
Paradigma de una sin par operación reductora del Derecho a la legislación, la codificación "absolutiza" el fenómeno jurídico y se lo entrega al Estado en régimen de monopolio, y a la luz de un empeño que nada tiene de constitucional. La "carga invisible" de la operación (en los términos de Tomás y Valiente), todavía pesa. Así lo denunciaba no hace mucho, en ocasión solemne, un jurista de tan profunda sensibilidad histórica como Paolo Grossi:

"Sea ya por la lucidez del proyecto jurídico burgués, ya por su carga de despotismo, ya por la pereza proverbial del cuerpo de los juristas, sea por lo uno o por lo otro, estatualidad (sic) del derecho, monopolio de la ley, función pasiva de la iurisprudentia son factores que se han mantenido prácticamente intactos, al menos para la convicción difusa de la mayoría silenciosa de los juristas"15.

Toda una tradición, de larga impronta, que depositaba en los jueces una función de contrapeso del poder quedó cancelada con la construcción del Estado de Derecho y su traducción teórico-positivista en el terreno de la ciencia jurídica. Desde las célebres palabras de Robespierre, condenatorias de la jurisprudencia, pero donde todavía cabe la Constitución (Ce mot de juriprudence des tribunaux doit être effacé de notre langue. Dans un état qui a une constitution, une legislation, la jurisprudence des tribunaux n'est autre chose que la loi), se desemboca, en línea directa, en el juez como mera vox legis o "autómata de la subsunción" (subsumzionsautomat), lo que vino a dar un tardío, pero completo triunfo, a las ideas de Montesquieu ${ }^{16}$.

En este particular extremo, no hay diferencias significativas entre las distintas corrientes interpretativas que dominan la

\footnotetext{
15 “El punto y la línea. Historia del Derecho y derecho positivo en la formación del jurista de nuestro tiempo", Lección magistral en el acto solemne de investidura como doctor honoris causa del profesor Paolo Grossi, Sevilla, Universidad de Sevilla, 1998, p. 21.

16 Al respecto puede verse el trabajo de Massimo La Torre "II potere ambiguo. La figura del giudice tra la democrazia francese e il Rechtsstaat tedesco", Sociología del Diritto, 2, 1999, pp. 37 y ss.
} 
escena jurídica, en Francia y en Alemania, durante la primera mitad del siglo XIX, la de la exégesis y las dogmática e histórica ${ }^{17}$.

Precisamente al Ihering de la segunda etapa, el de la jurisprudencia "de intereses", defendida en una obra de 1877 , Der Zweck im Recht (el Fin en el Derecho), se debe la siguiente reflexión, diametralmente antitética con respecto a lo que había sido el ideal del constitucionalismo:

"Es un error creer que el interés o la seguridad de los derechos y de la libertad política requieren el máximo posible de limitaciones de la autoridad del Estado por medio del Derecho. Ello es consecuencia de la extraña convicción de que la fuerza es un mal que hay que contener al máximo. La fuerza es, en realidad, un bien; aunque, al igual que todos los bienes, sólo puede ser utilizada de manera saludable, y teniendo en cuenta la posibilidad de abusos". Y concluye así: "El único medio de prevenir los abusos no consiste en encadenar la fuerza; hay otro mucho más eficaz, reside en la responsabilidad personal"18.

Desde la perspectiva positivista, parece evidente que la Constitución es Derecho del poder, no de la libertad. La construcción dogmática del Derecho Público nace con esa impronta genética y, a partir de la misma, construye un sólido arsenal conceptual que trasluce cierta mística estatalista de sesgo autoritario. Las palabras utilizadas por Anschütz, "Aquí desaparece el derecho público", para referirse al modo (extrajurídico) en que se resolvió el conflicto constitucional prusiano de 1862-66, son lo suficientemente expresivas al respecto ${ }^{19}$.

17 Cfr. Franz Neumann, The rule of Law. Political theory and the Legal system in modern society, Heilderberg, Berg Publishers, 1986, pp. 226 y ss. El "diálogo" entre Savigny, representante por excelencia de la llamada escuela histórica, y su discípulo lhering, defensor inicial de una construcción "dogmática" o de conceptos, en evolución posterior hacia una llamada "de intereses", puede verse en P. Casanovas y J. Moreso, eds., El ámbito de lo jurídico. Lecturas de pensamiento jurídico contemporáneo, Barcelona, Crítica, 1994, pp. 22 y ss.

18 Rudolf Ihering, El fin en el Derecho, Buenos Aires, Heliasta, 1978, pp. 203-204, bajo el epígrafe "Límites de la sumisión del poder público a la ley".

19 Cit. por Forsthoff, El Estado de la sociedad industrial, Madrid, Instituto de Estudios Políticos, 1975, p. 17. 
La teoría del Estado-persona fue formulada en Alemania por Gerber, en 1865, con el fin de combatir la concepción patrimonial del poder, que hace del Estado un patrimonio del Príncipe, y de la facultad de mandar un derecho subjetivo del rey ("La tierra y la gente - escribe Gerber en sus Grundzüge des deutschen Staatsrechts - han salido de la esfera patrimonial del Príncipe, los súbditos se han constituido como pueblo unido con conciencia nacional, y de esta concepción ha surgido en las nuevas leyes constitucionales el Estado como un organismo constitucional autónomo, y el Príncipe ha cambiado su antigua situación como sujeto jurídico fuera del Estado por su situación como órgano de voluntad supremo ${ }^{20}$.

El objetivo de Gerber era el de realizar una construcción sistemática del Derecho Político vertebrada jurídicamente y liberada de las adherencias filosóficas e históricas que habían imperado hasta entonces. La doctrina del Estado había de ser puramente jurídica y, para conseguirlo, el Estado tenía que ser tratado como sujeto de derecho, es decir, como persona jurídica. La consideración del Estado como un ente personal aparecía así como la premisa necesaria para toda la construcción jurídica del Derecho Público. "De Gerber - dice Fernando de los Ríos en su prólogo a la traducción, efectuada por él mismo, de la Teoría General del Estado, de Jellinek - arranca el moderno Derecho Político alemán y, aun hasta cierto punto, la concepción general que ha prevalecido durante algún tiempo en la Europa continental en lo que a esta disciplina jurídica respecta”.

La misma pretensión metodológica, depuradora de cualquier elemento ajeno a lo rigurosamente jurídico, se advierte en la obra de Paul Laband, de 1876, Das Staatsrechts des deutschen Reiches. Para él, método jurídico significa análisis lógico-formal de las normas de derecho positivo:

20 Cfr. Joaquín Tomás Villarroya, "La dirección dogmática en el Derecho Público", en Estudios de Filosofía del Derecho y Ciencia jurídica en memoria y homenaje al catedrático D. Luis Legaz y Lacambra, Madrid, Centro de Estudios Constitucionales, 1985, pp.731 y ss. 
"le rôle scientifique de la dogmatique - escribe en el prólogo de la segunda edición - dans un droit positif déterminé consiste à analiser les formes juridiques, à ramener les notions particulières à des principes plus généraux et à déduire de ces principes les conséquences qu'ils impliquent (...)"21.

Una geometría jurídica que, como se ha dicho, cerraba cualquier vía de penetración al "espíritu 1789", formando una realidad autónoma con respecto a otra realidad más real (si se nos permite la chanza): un imperio de 25 Estados, bajo la hegemonía de Prusia, con un Kaiser a la cabeza, dotado de facultades omnímodas en materia de política exterior y mando del ejército, y comprometido en una política de contención de la clase obrera ${ }^{22}$.

Con la teoría del órgano, la "mística estatalista" quedará elevada a su máxima expresión, como lo atestigua el lenguaje utilizado por Santi Romano, el más entusiasta cultivador de dicha teoría, sobre la estela de lo ya apuntado por Gierke:

"Impersonalidad del poder público, o mejor, personificación del poder por medio del Estado, concebido él mismo como persona: he ahí el principio fundamental del derecho público moderno, una persona inmaterial, pero real; una entidad no ficticia o imaginaria, pero que, pese a no tener cuerpo, actúa mediante delicados y maravillosos dispositivos jurídicos, con el objetivo de formar, manifestar e imponer su propia voluntad. No sombra o espectro, sino verdadero principio vital que deviene operativo por medio de un organismo, en el genuino y estricto significado de la palabra, con la ayuda de un conjunto de instituciones, dispuestas y coordinadas al servicio de la realización de aquel objetivo" 23 .

\footnotetext{
21 Cito por la traducción francesa, Paul Laband, Le Droit Public de I'Empire Allemand, París, Giard e Brière, 1900, pp. 9-10.

22 Cfr. Álvaro Rodríguez Bereijo, "Laband y el Derecho presupuestario del Imperio alemán", "Estudio preliminar" a Paul Laband, Derecho Presupuestario, Madrid, Instituto de Estudios Fiscales, 1979, passim.

23 Santi Romano, Lo Stato moderno e la sua crisi. Saggi di Diritto Costituzionale, Milán, Giuffrè, 1969, p. 8.
} 
La personalidad jurídica del Estado resulta ser una eficaz solución para encubrir con anaqueles de sofisticada doctrina el conflicto político de fondo. La persona estatal tiende a identificarse con el complejo Corona/Ejecutivo, y a arrinconar al Parlamento, al que se considera más bien cosa de la sociedad ${ }^{24}$.

Jellinek completa la tríada de gigantes del Derecho Público alemán decimonónico. Su sincretismo metodológico, plasmado en la famosa Zwei-Seiten Theorie (el Estado como construcción social y como institución jurídica, con las dos doctrinas del Estado consiguientes, la social y la jurídica), le permite aproximarse al fenómeno estatal de manera mucho más acabada de lo que lo habían hecho el organicismo de Gerber y el exaltado positivismo de Laband. Impresiona la erudición que acredita en su Teoría General del Estado, con sus lúcidas y penetrantes introducciones históricas a cada una de las instituciones de un Derecho Público, que ya no es puro formalismo more geometrico, pero en el que el Estado sigue apareciendo, al igual que en las obras de Gerber y Laband, como un poder supremo dotado de fuerza para imponer sus decisiones:

"La nota esencial de un Estado es la existencia de un poder del mismo. Este poder no puede derivarse de otro ninguno, sino que tiene que proceder de sí mismo y según su propio derecho. El contenido de este poder de dominación es completamente indiferente para su existencia. Alí donde haya una comunidad con un poder originario y medios coercitivos para dominar sobre sus miembros y su territorio, conforme a un orden que le es propio, allí existe un Estado"25.

El Estado de Derecho se distingue del Estado absoluto, no por su diversa naturaleza, sino únicamente por la contingente decisión de autolimitarse que realiza el primero (Selbstbindung des Staates). Decisión, la de autolimitarse, que de más está decir que

24 Cfr. Luis López Guerra, "Sobre la personalidad jurídica del Estado", Revista del Departamento de Derecho Político de la UNED, 6 [1980], pp. 17 y ss.

25 Georg Jellinek, Teoría General del Estado, Buenos Aires, Albatros, 1978, pp. 367-368. 
es revocable ad libitum por el Estado mismo. En la llamada línea Gerber-Laband-Jellinek, la juridicidad o el derecho son, como se ha dicho, "atributos accidentales de una esencia del Estado"26.

Desde nuestra perspectiva actual, es en el encuadramiento de los derechos dentro del conjunto del sistema donde una construcción como la realizada por Jellinek manifiesta todas sus carencias. Como es sabido, Jellinek sostuvo una encendida polémica con el francés Boutmy acerca de las influencias que acusaba la Declaración francesa de 1789, colonial-norteamericana, y de carácter religioso, para el primero; de matriz roussoniana y carácter político, para el segundo ${ }^{27}$.

Sintetizando ideas desarrolladas in extenso en su System der subjektiven öffentlichen Rechts (Sistema de los derechos públicos subjetivos), Jellinek concluye su trabajo sobre la Declaración con un Apartado dedicado a "Los derechos del hombre y la concepción germánica del Derecho”. El espacio de libertad del individuo viene ahí considerado no como un derecho, sino como una situación de hecho:

"Esta libertad no se crea por el Estado, se reconoce por él, y eso limitándose a sí propio y determinando los espacios que deja libres y que necesariamente deben existir, en la trama de las normas que rodean al individuo. El espacio libre así definido, más que un derecho es una situación de hecho. El gran error del derecho natural consiste en considerar este estado de hecho de la Libertad como un Derecho, y reconocer en ese Derecho una superioridad que habrá creado el Estado y limitado su poder" (Jellinek, "La Declaración de los Derechos del Hombre y del Ciudadano", p.119).

26 Cfr. Massimo La Torre, “Un jurista en el crepúsculo de Weimar. Política y Derecho en la obra de Herman Heller", Estudio preliminar a Herman Heller, El sentido de la política y otros ensayos, Valencia, Pretextos, 1996.

27 La polémica puede seguirse en la edición preparada por Jesús Amuchástegui, Orígenes de la Declaración de Derechos del Hombre y del Ciudadano, con los trabajos centrales de JeIlinek y Boutmy, y los colaterales de Doumergue y Adolfo Posada, Madrid, Editora Nacional, 1984. 
En la teorización del Estado liberal de derecho no es posible fundar los derechos y la libertad sobre el estado de la naturaleza y la derivación contractual. No hay contraposición alguna entre unos derechos naturales de los individuos (escritos así, con minúscula, como seguimos haciendo por inercia que probablemente es más que gramatical) y un Derecho positivo del Estado (naturalmente con mayúscula). Sólo en el seno del derecho positivo puede hallarse el fundamento de unos derechos que no son expresión de valores precedentes, sino resultado y efecto de las normas mediante las cuales el Estado accede a autolimitarse.

Los derechos de libertad, al igual que los derechos subjetivos in genere, tienen así algo de contradictorio: se fundan (paradójicamente) en un estado de ausencia completa de derechos, y en condiciones de absoluta subordinación al poder estatal (el status subjectionis de la teoría de los derechos públicos subjetivos, de Jellinek). En su base ya no están aquellos derechos que se presuponen plenos hasta que una norma de la autoridad no los limite, sino el Estado, cuya soberanía se presupone plena en la medida en que él mismo no la limite con un acto de voluntad constitutivo de los derechos de los individuos ${ }^{28}$.

Y la posición del juez, en un sistema con principios de carácter tan estatalista, no puede dejar de resentirse:

“(...) es difícil que el juez - no importa si ordinario o administrativo - sea completamente libre para tutelar los derechos individuales en el momento en que éstos chocan con las razones de la autoridad. En efecto, el juez de que se trata no es depositario de un ideal de garantía autónomamente fundado en la Constitución - como en el caso estadounidense -, sino que es expresión de la soberanía del Estado, de tal manera que, en plenitud, no puede aparecer como un tercero neutral entre las razones individuales de los particulares y las razones de la autoridad pública y de la burocracia del Estado"29.

28 Cfr. Fioravanti, Los derechos fundamentales..., cit., Cpt. 3, “El lugar de las libertades en las doctrinas de la época liberal".

29 Fioravanti, Los derechos..., p. 120. 
En el punto central del sistema, esto es, en la reformulación del poder soberano, como soberanía del Estado, hay una coincidencia entre la "línea Gerber-Laband-Jellinek", la "relectura" de la soberanía de la Nación y de la propia Revolución francesa, verificada, con diversas variantes, por los iuspublicistas de la Tercera República, con Carré de Malberg a la cabeza, e incluso la analytical jurisprudence de un Jeremy Bentham y un John Austin.

Así, Duguit asimila el Estado a los gobernantes. Hauriou lo define como una institución; Esmein y Carré de Malberg lo presentan, en fin, como la personificación jurídica de la Nación.

El esfuerzo teórico de Carré es especialmente notable en lo que tiene de interpretación global de la convulsa experiencia constitucional francesa en clave de progresiva afirmación de la soberanía del Estado, frente a los elementos disgregadores de carácter individualista (derechos de la Declaración), y también de tipo contractualista (voluntad de los ciudadanos como origen del pacto constituyente) $)^{30}$.

Carré formula en términos muy técnicos las dos ideas típicas del positivismo jurídico: la total identificación del derecho con el derecho del Estado, y el carácter de la Constitución como supremo acto de ejercicio del poder estatal. "Al jurista - escribe Carré - no le compete otra cosa que constatar que el Estado se encuentra formado a partir del momento en que la comunidad nacional, asentada sobre un territorio, posee de hecho órganos en disposición de expresar la voluntad de aquél, y capaces de establecer un orden jurídico, e imponer con carácter supremo su potestad de mando. La cuestión del procedimiento mediante el cual tales órganos se han constituido, no es que no sea el problema capital de la ciencia del Derecho Público, sino que no es, en absoluto, un problema jurídico (...). En el fondo, todas las observaciones hasta aquí realizadas se reducen a esta verdad, aparentemente ingenua, pero bien profunda: el Derecho

30 Cfr. Marie-Joëlle Redor, «L'Etat dans la doctrine publiciste française du début du siècle», Droits, 15 [1992], pp. 91 y ss. 
Constitucional presupone siempre una constitución en vigor. $\mathrm{Y}$ así, por Derecho Constitucional hay que entender no un derecho cuyo objeto sería constituir el Estado, sino un derecho que sólo existe en el seno de un Estado ya constituido, y provisto de órganos en normal funcionamiento" 31 .

Se asiste, en definitiva, a un triunfo a título póstumo de la filosofía hegeliana, donde el Estado aparece como encarnación de lo racional, como el mundo hecho espíritu y como libertad en plenitud de realización, según expone Hegel en el bien conocido pasaje de sus Elementos de filosofía del Derecho:

"El Estado, en sí y por sí, es la totalidad ética, la realización de la libertad (...). El Estado es el espíritu que está en el mundo, y se realiza en el mismo con conciencia (...). El ingreso de Dios en el mundo es el Estado; su fundamento radica en la potencia de la razón que se realiza como voluntad. En la idea de Estado no deben tenerse presentes situaciones particulares, instituciones concretas; por contra, debe considerarse, por sí misma, la idea de este Dios real. (...). Las determinaciones de la voluntad individual son llevadas, mediante el Estado, hacia una existencia objetiva, y alcanzan sólo a través de él su verdad y realización. El Estado es la única condición para la realización del fin y bienestar particular" 32 .

Al doblar el siglo, el eco democrático de la Revolución francesa, y el del constitucionalismo, había quedado, en definitiva, sepultado por la ensordecedora presencia de la hiper-formalista doctrina jurídica del Estado. Y la consideración de los derechos tendía a circunscribirse, como apunta Smend, a "un simple y caduco rechazo de las limitaciones históricas - feudales o absolutistas - de la libertad individual"33.

31 Contribution à la theorie générale de l'Etat, París, reimpr. CNRS, 1992, t. II, pp. 492 y 499.

32 Lineamenti di Filosofia del Diritto, epígrafes 258 y 261, recogido en John M. Kelly, Storia del pensiero giuridico occidentale, Bolonia, II Mulino, 1996, p. 384.

33 Rudolf Smend, "Ciudadano y burgués en el derecho político alemán", recogido en Constitución y Derecho Constitucional, Madrid, Centro de Estudios Constitucionales, 1985, p. 254. 


\section{Democratización y fractura teórica}

"La ortodoxia de que ha vivido políticamente el siglo XIX - concluía Fernando de los Ríos en su Estudio Preliminar a la obra capital de Jellinek - (...) se ha roto. Sus afirmaciones esenciales de carácter doctrinal, la soberanía como rasgo jurídico característico del Estado, o es desechada (...), o es concebida de muy distinta suerte (...). Los derechos individuales sufren una transformación substancial en su justificación, y el civilismo (sic) de que está invadido el Derecho Político pugna por ser arrojado fuera (...)".

Y concluye con siete líneas, en las que realiza un encendido canto a la (llamada por él mismo) "la categoría de la libertad":

"La solución (a la situación de crisis recién descrita) ha de arrancar de la fundamentación de un criterio intervencionista, criterio del que carece la moderna Ciencia política. Este criterio sólo puede suministrarlo un análisis de la idea de libertad, verdadero fundamento, categoría radical de la vida civil, de donde ha de emerger el sistema de condiciones que ha de hacer posible a la voluntad jurídica (...) que cada hombre pueda resolver el problema trascendental de su vida: la vocación”.

El "criterio intervencionista" que Fernando de los Ríos echara en falta a la hora de fundamentar el Derecho Político, todavía había de demorarse unos años. Este sector de la ciencia jurídica sólo se había hecho respetable a costa de expulsar de su seno cualquier vestigio de las originarias señas de identidad del constitucionalismo. Pero la gran quiebra social provocada por la desaparición de los supuestos que estaban en la base del Estado liberal, hará del período que transcurre entre las dos guerras mundiales, y especialmente allí donde la quiebra fue más acusada, el momento del apogeo de un debate que ahora ya no puede eludirse.

Se trata del debate de siempre, el de la naturaleza y los límites del poder político, pero revivificado con el bagaje conceptual procedente de los saberes que el siglo XIX había ido asentando: el jurídico y el sociológico. El resultado es un 
replanteamiento polémico y radical de la cuestión del fundamento de la Constitución y de la cualidad de la misma para conformar la vida social.

El "colapso del imperio liberal" (por decirlo según el título de la conocida obra de Goldstene), tanto en la vieja Europa como en los Estados Unidos, hace que resurja, en efecto, algo hacia lo que la ideología dominante durante el siglo XIX había sentido profunda aversión : el problema del poder político, el de su titularidad y el de su reparto ${ }^{34}$.

La estabilidad del mundo liberal deja así paso a la incertidumbre del mundo posbélico. "La diferencia más importante - escribe Lukács - entre el mundo de anteguerra y el de posguerra es, sin duda alguna, la fuerte conmoción primero, y más tarde la pérdida casi total, del sentimiento de seguridad en cuanto a la existencia social e individual" ${ }^{35}$.

La "racionalización" del poder es la respuesta mediante la cual el constitucionalismo de la época intentará reconducir el potencial revolucionario, o disolvente, abierto por las nuevas marcas distintivas de aquél: universalización del sufragio, tendencia hacia la proporcionalidad de la fórmula electoral, reconocimiento de instrumentos de participación directa, nuevas responsabilidades del Estado en la dirección de la vida económica, ampliación del listado de derechos, etc. Pero la operación tendrá sus límites, y el marasmo de la política acabará haciendo (provisionalmente) inútil el esfuerzo racionalizador ${ }^{36}$.

\footnotetext{
34 Paul Goldstene, The Collapse of Liberal Empire, New Haven, Yale University Press, 1977.

35 Georg Lukács El asalto a la razón, Barcelona, Grijalbo, 1976, pp. 68-69. Stefan Zweig, en sus memorias El mundo de ayer, Barcelona, El Acantilado, 2001, pese a afirmar que "es mucho más fácil reconstruir los hechos de una época que su atmósfera espiritual" (p. 264) (o quizá por eso mismo), describe con eficacia difícil de superar los cambios que se fueron produciendo en la mentalidad social a partir del final de la Gran Guerra.

36 Cfr. Javier Corcuera, “El constitucionalismo de entreguerras: la racionalización del poder y sus límites", en Estudios de Derecho Público. Homenaje a Juan José Ruiz Rico, Madrid, Tecnos, 1997, vol. I, pp. 55 y ss.
} 
Todo ese arsenal de cambios sociales e innovaciones constitucionales necesariamente tenía que producir, como produjo, la ruptura de la ortodoxia positivista. Ésta se reveló incapaz de seguir teniendo éxito en su pretensión de situar el fenómeno jurídico a resguardo de contaminaciones de lo político. El sometimiento del Estado al Derecho dejó de tener la función legitimadora que le había caracterizado hasta entonces, y la propia ciencia de lo jurídico hubo de abandonar la aureola sagrada con la que aspiraba a perpetuarse en los anaqueles. Como ha escrito Estévez Araujo,

“(...) la radical separación del Derecho y la política presupone que los juristas no cuestionan la legitimidad del régimen político. Pero sobre todo, es la coincidencia generalizada de los valores políticos sustentados por los juristas y los contenidos del sistema jurídico, lo que crea la apariencia de que las operaciones de construcción de conceptos son 'puramente lógicas'. La pretendida ausencia de lagunas en que la dogmática basaba la autonomía del derecho, no es propiedad intrínseca del derecho, sino producto de la actitud ideológica, de la fetichización del derecho" 37 .

El Principio monárquico, el moderantismo doctrinario y la Teoría del Estado habían hecho que el concepto revolucionario de Constitución - el que acostumbramos a llamar aún hoy concepto racional normativo - cayera en el olvido. El derecho se había convertido en un fetiche, y el pensamiento jurídico, ya desde el nombre con el que autoproclamaba su carácter, era un modelo de pensamiento dogmático.

Todo eso se viene abajo en el período de entreguerras. El pensamiento de carácter jurídico-político se adentra en el campo del saber investigador, y arroja sus frutos con la aparición de lo que podemos llamar "fragmentos de teoría constitucional"; más bien diferentes teorías que tratan de aportar las respuestas

37 José A. Estévez Araujo, Schmitt en Weimar. La crisis del Estado de Derecho liberal, BarceIona, Ariel, 1989, pp.90-91. 
que el constitucionalismo liberal y el positivismo jurídico, con su normologismo vacío, ya no son capaces de dar. Eso ocurre, como es bien sabido, en un ámbito espacial-temporal bien determinado, la Alemania de la Constitución de Weimar, "microcosmos científico-cultural del constitucionalismo continental europeo", por decirlo con palabras de Lucas Verdú ${ }^{38}$.

Varias generaciones de tratadistas españoles de Derecho Político, a partir de la Segunda República, deben (o debemos) buena parte de nuestra formación al influjo de unas teorías, que se forjaron en el fragmentado y polarizado clima político de Weimar. Es posible que ello llegara a producir cierto apego obsesivo, hoy del todo injustificable. Pero, sea como fuere, pocas dudas caben de que, si la teoría constitucional ha alcanzado hoy un nivel satisfactorio, es porque ha sido edificada "sobre los lomos de determinados gigantes".

Pocas cosas podrían explicarse hoy, cuando menos en Europa, sin haber captado (y acaso dejado de lado) la confrontación entre las ideas relativas a la defensa de la Constitución de Kelsen y Schmitt. Y muy pobre concepto de Constitución seríamos capaces de dar si prescindiéramos de las aportaciones en materia de dinámica constitucional de Heller o Smend.

Entre la obra de Hans Kelsen (1881-1973) y la de Carl Schmitt (1888-1985) discurre un sutil hilo que vincula a ambas a partir de la identidad de las cuestiones planteadas por los dos autores.

El positivismo había dado la vuelta a Thomas Paine ("La Constitución de un país no es el acto de un Gobierno, sino del pueblo que constituye su Gobierno"), y había entendido que la Constitución es el producto de la voluntad del Estado. Si la Constitución es acto del Estado, ¿cómo puede, al mismo tiempo, ser el presupuesto de la legitimidad de los actos del Estado? O dicho de otro modo: ¿dónde radica el fundamento de la validez del derecho?

38 Pablo Lucas Verdú, La lucha contra el positivismo jurídico en la república de Weimar. La teoría constitucional de Rudolf Smend, Madrid, Tecnos, 1987. 
La teoría de Schmitt hace de las limitaciones y de las debilidades de la democracia parlamentaria el leit motif que lleva al autor a una condena sin paliativos de la práctica del Estado constitucional. La denuncia de las contradicciones en que éste habría incurrido desembocan en un juicio negativo sobre la legitimidad del sistema, y en la reivindicación de un modelo alternativo, basado en el decisionismo y el caudillaje

Schmitt distingue, como de sobra es conocido cuatro conceptos de Constitución: absoluto, relativo, ideal y positivo ${ }^{39}$.

El concepto absoluto significa "la Constitución como un todo unitario", y puede, a su vez, ser entendido de dos formas distintas: como unidad política del Estado realmente existente, o como unidad concebida, esto es, normativa. En el primer caso, significa "la concreta situación de conjunto de la unidad política y ordenación social de un cierto Estado"; en el segundo, la "regulación legal fundamental, es decir, un sistema de normas supremas y últimas". En polémica con las concepciones de Kelsen, Schmitt sitúa esta última acepción en el contexto histórico de la Monarquía francesa de la Restauración, un sistema en el que "los representantes del liberalismo burgués" han calificado a la Charte de soberana. Con la diferencia respecto a Kelsen, de que el Derecho natural racional daba allí la apariencia de sistema, orden y unidad que, en la teoría de este último, se desvanece, dejando así a la norma positiva desprovista de cualquier elemento legitimador externo: "(las normas positivas) no valen porque en justicia deban valer, sino sólo porque son positivas, sin consideración a cualidades como razonabilidad, justicia, etc".

El concepto relativo de Constitución hace que ésta equivalga a "la ley constitucional en particular". La Constitución única se disuelve en "una pluralidad de leyes constitucionales distintas, formalmente iguales", con lo que el significado de la

39 Carl Schmitt, Teoría de la Constitución, Madrid, Alianza, 1982, Sección Primera (Concepto de Constitución), passim. 
Constitución experimenta un doble proceso, de relativización de sus contenidos, y de formalización indiferenciada de su proceso de adopción y reforma.

El concepto ideal es el que se fija en el contenido de la Constitución, aceptando sólo como "verdadera" o "auténtica" aquella que responde a un cierto ideal de Constitución. Se trata, según Schmitt, de un concepto que ha hecho tanta fortuna que "desde el siglo XVIII sólo se han designado como Constituciones aquellas que correspondían a las demandas de libertad burguesa y contenían ciertas garantías de dicha libertad".

Por fin, la Constitución en sentido positivo surge mediante un acto del poder constituyente, y "contiene sólo la determinación consciente de la concreta forma de conjunto por la cual se pronuncia o decide la unidad política”. Para llegar ahí, Schmitt denuncia como inadmisible el empeño de "disolver primero la Constitución en una pluralidad de leyes constitucionales concretas, y determinar después la ley constitucional por algunas características externas o acaso por el procedimiento de su reforma”. El concepto de Constitución es únicamente posible a partir de la diferencia ente Constitución y ley constitucional:

“(...) la esencia de la Constitución no está contenida en una ley o en una norma. En el fondo de toda normación reside una decisión política del titular del poder constituyente, es decir, del Pueblo en la Democracia y del Monarca en la Monarquía auténtica" ${ }^{40}$.

La Constitución es, pues, decisión. "Se apoya en una decisión política surgida de un Ser político, acerca del modo y forma de del propio Ser", mientras que la ley constitucional no es sino "la normación que lleva a la práctica la voluntad constituyente" ${ }^{41}$.

El decisionismo de Schmitt, y la tesis del poder constituyente puesta en acto por el constitucionalismo de impronta liberal, se asemejan en la separación que las dos realizan entre

\footnotetext{
40 Teoría de la Constitución, p. 47

41 Teoría de la Constitución, p. 94.
} 
unidad política soberana y orden jurídico. En los dos casos, dicha unidad política, tildada de soberana, existe (en la Nación, en el Pueblo o en el Estado) como un dato anterior al orden jurídico positivo y con independencia de éste.

La diferencia estriba en el modo, por así decir realista y desmitificador, con el que Schmitt se enfrenta al asunto. El carácter indeciso con que aquel constitucionalismo dicho liberal afronta el problema del poder soberano, atribuyendo el ejercicio de éste a una entelequia, como la Nación, por sí sola o con el Rey, o bien al Estado - como ocurre en el caso de las tesis positivistas - deja paso, en el pensamiento de Schmitt, a la realidad descarnada de la actividad política. Ésta es concebida como una actividad humana cuyo objeto es operar la separación entre el amigo y el enemigo:

“(..) la distinción política específica, aquella a la que pueden reconducirse todas las acciones y motivos políticos, es la que distingue amigo y enemigo. Lo que ésta proporciona no es desde luego una definición exhaustiva de lo político, ni una descripción de su contenido, pero sí una determinación de su concepto en el sentido de un criterio" ${ }^{42}$.

Así pues, si la Constitución es la decisión global sobre la especie y la forma de la unidad política, lejos de ser el producto de un pacto conciliatorio, se convierte en la línea de demarcación entre la amistad y la enemistad políticas. Es la decisión de aquella parte de la colectividad que ha conseguido excluir a la otra. La Constitución como decisión proporciona además un criterio de interpretación: ésta debe ser interpretada como si fuera el producto de una voluntad unitaria y coherente. Su funcionalidad última reside precisamente en ser el instrumento mediante el cual se identifica al enemigo y se le excluye de la legalidad. Un criterio interpretativo al servicio de un objetivo bien concreto y determinado: la defensa del traspaso, vía artículo 48 de la Constitución de Weimar, de las potestades

${ }^{42}$ Carl Schmitt, El concepto de lo político, Madrid, Alianza, 1991, p. 56. 
parlamentarias hacia el presidente del Reich, legitimado como "señor de la Constitución" ‘3.

A la idea schmittiana conforme a la cual la Constitución es una decisión concreta del pueblo, entendido como unidad política presupuesta, es decir, del pueblo entendido no como abstracta base social de las instituciones, sino como sujeto político unitario y activo, en cuanto que resultado de la confrontación amigo/enemigo, se opone la concepción kelseniana de la Constitución, entendida como norma fundamental presupuesta.

Kelsen representa el punto de llegada de la línea emprendida por Gerber, y continuada por Laband y Jellinek, llevando hasta sus últimas consecuencias la consideración del Estado como un orden jurídico. Con él, señala Tomás Villarroya, puede considerarse plenamente culminada la labor depuradora que se había planteado como objetivo la llamada dirección dogmática del Derecho Público ${ }^{44}$. En tanto que autor de la que pasa por ser la más importante teoría jurídica del siglo XX, ninguna polémica de la reflexión jurídica actual resulta comprensible prescindiendo de una doctrina que es casi siempre el punto de partida, cuando no el centro, de tales polémicas ${ }^{45}$. Y si esto es así con respecto a la teoría jurídica, si hablamos de teoría constitucional, o de constitucionalismo a secas, es difícil no elevar a categoría absoluta afirmaciones del estilo de las recién transcritas. La teoría de Kelsen es para la teoría constitucional de nuestros días lo que fue el pensamiento de un Montesquieu, de un Rousseau o de un Sieyés, en el momento de la edificación del Estado Constitucional; un pensamiento pragmático y actuante, que vivificó para siempre el lugar de la Constitución en el sistema jurídico, y aportó al Derecho Constitucional la

\footnotetext{
43 Cfr. José A. Estévez Araujo, La crisis del Estado de Derecho liberal, cit., Capítulo V (“Schmitt contra Weimar. El segundo modelo: la dictadura plebiscitaria del presidente del Reich"). 44 Joaquín Tomás Villarroya, "La dirección dogmática en el Derecho Público", cit. nota 81 p. 737.

45 Cfr. Albert Calsamiglia, Kelsen y la crisis de la ciencia jurídica, Barcelona, Ariel, 1978, "Introducción".
} 
dignidad que hasta entonces no había tenido. Hablando en ese sentido, nos atrevemos a disentir de opiniones tan rotundas, $y$ de fuente tan autorizada, como las de Karl Larenz, quien, tras calificar a la teoría pura del derecho como "el más grandioso intento de elevar el saber jurídico a la categoría de ciencia", establece un paralelismo entre la teoría pura y la llamada jurisprudencia de intereses en los siguientes términos:

"Así como la jurisprudencia de intereses fue defectuosa como teoría, pero de gran utilidad práctica, la teoría pura del derecho es muy seductora como teoría, pero su contribución práctica resulta escasa" 46 .

Muy al contrario, la obra de Kelsen debe ser considerada como la imprescindible bisagra teórica entre los viejos planteamientos y los nuevos. De un lado, como ha escrito gráficamente Francesc de Carreras, "supone la culminación jurídica del formalismo propio del Estado liberal garantista; de otro, introduce los dos elementos que subvertirán el orden antiguo y serán la clave para el nuevo Derecho Constitucional: la Constitución como norma suprema que condiciona la validez de todo el ordenamiento y la garantía jurisdiccional de esta validez en forma de tribunal especializado" ${ }^{47}$.

Pero retomemos el hilo de la exposición y volvamos a los planteamientos de fondo. De entrada, es significativo que, tanto Schmitt como Kelsen, necesiten recurrir a un elemento ficticio para fundamentar su idea de Constitución. Los dos utilizan el verbo presuponer, es decir (conforme a la precisa definición del Diccionario de la Real Academia), "dar antecedentemente por sentada, cierta, notoria y constante una cosa para pasar a tratar de otra”. Presuponer una unidad política particular y concreta significa presuponer una guerra civil de la que se ha salido como vencedor. Presuponer una norma fundamental general y

\footnotetext{
46 Karl Larenz, Storia del metodo nella Scienza giuridica, Milán, Giuffré, 1966, pp. 95-96.

47 Francesc de Carreras, "Prólogo" a M. Barceló, Derechos y deberes constitucionales en el Estado autonómico, Madrid, Cívitas, 1991, p. 26.
} 
abstracta como fundamento de todo el derecho vinculante para todos, significa dar por sentado que hay un "deber" de respeto pacífico al derecho, que es asumido por todos como obligatorio.

Kelsen distingue entre Constitución en sentido lógicojurídico, y Constitución en sentido jurídico-positivo. Y en este último sentido, la Constitución es contemplada desde dos puntos de vista: el de su contenido, y el del fundamento de su validez. Desde el punto de vista del contenido, Kelsen acoge una diferenciación que va a tener gran influjo posterior: la que distingue entre Constitución "en sentido formal", y Constitución "en sentido material". Desde el punto de vista del fundamento, la diferencia está entre constituciones que aparecen por vez primera, en términos históricos, y constituciones que derivan su validez de otra anterior.

"Si, por de pronto, - escribe Kelsen - se observa un orden jurídico estatal, el estrato superior jurídico positivo, está representado por la constitución. Por constitución se entiende aquí la constitución en un sentido material, es decir, con esa palabra se designa la norma o normas positivas que regulan la producción de las normas jurídicas generales (...). De la constitución en sentido material, corresponde distinguir la constitución en sentido formal, esto es, el documento denominado 'constitución' que, como constitución escrita, no sólo contiene normas que regulan la legislación, esto es, la producción de normas jurídicas generales, sino también normas que se refieren a otros objetos políticamente importantes, así como disposiciones según las cuales las normas contenidas en ese documento, la ley constitucional, no pueden ser derogadas o modificadas como simples leyes, sino sólo bajo condiciones más difíciles mediante un procedimiento especial (...)"48.

La búsqueda del fundamento de la validez de la constitución positiva le lleva a Kelsen a indagar cuál es la "constitución primera en sentido histórico", es decir, aquella que consiste en

48 Hans Kelsen, Teoría pura del Derecho, México, UNAM, 1981, pp. 232-233. 
un acto de producción jurídica que no es, a su vez, aplicación de norma positiva alguna:

"Si se pregunta ahora por el fundamento de validez de la constitución del Estado, sobre la cual reposa la validez de todas las normas (...), se llegaría quizá a una constitución del Estado más antigua. Esto es, se fundaría la validez de la constitución estatal existente en que se habría originado conforme a las disposiciones de una constitución estatal anterior, por vía de una enmienda constitucional conforme a la constitución (...). Y así se continuaría hasta llegar por fin a una primera constitución histórica del Estado, que no habría surgido por esa vía y cuya validez, en consecuencia, no puede ser referida a una norma positiva implantada por una autoridad jurídica. Es decir, se llegaría a una constitución del Estado implantada revolucionariamente $(. .) "$.49 .

Esta constitución, aprobada por vez primera en términos históricos, representa "la máxima autoridad jurídica". Pero, para la teoría pura, el problema no acaba ahí. A continuación es preciso responder a la pregunta acerca del fundamento de la validez de dicha máxima autoridad. En otros términos, hay que explicar cómo se pasa del "hecho" de la instauración primera a la "circunstancia generadora de derecho". La respuesta de Kelsen es del siguiente tenor:

"Si se considera solamente el orden jurídico estatal - y no el derecho internacional - y se pregunta por el fundamento de la validez de una primera constitución histórica estatal, (...) la respuesta sólo puede ser (...) que la validez de esa constitución, el suponer que es una norma obligatoria, tiene que ser presupuesta, si es que debe ser posible interpretar los actos realizados de acuerdo con ella como actos de producción o de aplicación de normas jurídicas generales válidas, y los actos realizados en aplicación de esas normas jurídicas generales, como la producción o aplicación de normas individuales válidas. Puesto que el

49 Teoría pura del Derecho, pp. 207-208. 
fundamento de validez de una norma sólo puede ser nuevamente una norma, el presupuesto de esa norma no puede ser una norma impuesta por una autoridad jurídica, sino una norma presupuesta (...). Como se trata de la norma fundante básica de un orden jurídico, (...) el enunciado que describe esa norma, el enunciado básico del orden jurídico estatal en cuestión, reza: los actos coactivos deben realizarse bajo las condiciones y en la manera que estatuyen la primera constitución histórica del Estado y las normas impuestas de conformidad con ella (en forma abreviada: uno debe comportarse como la constitución lo prescribe)" 50 .

Esa norma fundamental es, precisamente, la "constitución en sentido lógico-jurídico", el punto de partida del procedimiento de producción del derecho positivo, cuya esencia "se refiere inmediatamente a una determinada constitución, efectivamente impuesta, producida por la costumbre o promulgada expresamente (...), y mediatamente al orden coactivo producido conforme a esa constitución, también eficaz en términos generales, en tanto da fundamento a la validez de esa constitución y al orden coactivo producido de conformidad con ella" ${ }^{51}$.

El núcleo de la concepción kelseniana de Constitución se halla, pues, en el contenido de la norma fundamental, que es "la convicción de que la constitución es una norma vinculante". A la Constitución con fundamento en una unidad política concreta, resultado de la confrontación amigo/enemigo, Kelsen contrapone la Constitución basada en la difusa convicción de obligatoriedad compartida por toda la comunidad jurídica.

Mientras Schmitt cree que el fundamento de la Constitución está ya asentado en el plano del ser, y en el plano de lo que se desea seguir siendo, Kelsen lo fía todo a aquello que se considera que debe ser. Aquél se fija en una identidad victoriosa surgida en el pasado; éste en la asunción colectiva de un deber que se proyecta hacia el futuro. Schmitt insiste en el factor de la

\footnotetext{
50 Teoría pura del Derecho, p. 208.

51 Teoría pura del Derecho, p. 209.
} 
legitimidad, en el valor de la decisión, y en el de la orden concreta como instrumento de dominio; Kelsen sobredimensiona la legalidad, los procedimientos y la aceptación de reglas formales como vehículo para la convivencia. De tales contraposiciones nacen, como se ha dicho gráficamente, los espacios de libertad (como libertad igual para todos), implícitos en la teoría kelseniana, y los de ausencia de ella, característicos de Schmitt ${ }^{52}$.

En el haber de Kelsen hay que apuntar, sin duda, el haber salvado los aspectos formales del Derecho de la caída en el desorden y el caos por el que los contenidos de éste se estaban precipitando. El debe es el que tantas veces se ha apuntado: el concebir la ciencia del Derecho como una "geometría de la experiencia jurídica, que queda así reducida a forma huera y carente de entraña", así como elevar a categoría científica un "pathos de ausencia de pathos", que deja a la sociedad expuesta e inerme frente al fenómeno brutal del poder ${ }^{53}$.

La defensa del Estado de partidos y del parlamentarismo, que Kelsen realiza en su obra de 1920, Esencia y valor de la Democracia ${ }^{54}$, induce, sin embargo, a tomar con cierta reserva semejante tipo de críticas. Un componente esencial de la democracia es también el respeto a las formas y a los procedimientos, un respeto cuyo significado es profundo. Aceptar la producción regular de normas, con independencia de su contenido (dentro de los límites establecidos en la Constitución), y comprometerse a acatarlas, significa, en efecto, que ya no existen enemigos $a$ priori, puesto que también el derecho producido por los otros, si lo es en condiciones regulares, se acepta como derecho válido y vinculante.

La aportación de Rudolf Smend (1882-1975) recoloca la teoría constitucional en una corriente antipositivista cuyo influjo

\footnotetext{
52 M. Dogliani, Introduzione al Diritto Costituzionale, Bolonia, II Mulino, 1994, p. 242.

53 Gerhard Leibholz, "La formazione dei concetti nel Diritto Pubblico", Rivista Internazionale de Filosofia del Diritto (1931), pp. 269 y ss.

54 Kelsen, Esencia y valor de la Democracia, Méjico, Editora Nacional, 1980, en especial Cpts. II y III (“El Pueblo" y “El Parlamento").
} 
persiste hasta nuestros días. Frente a la celebérrima línea GerberLaband-Jellinek, con su punto de culminación en Kelsen, Smend puede ser presentado como la estación de partida de una nueva línea que se prolonga, sin solución de continuidad, hasta la influyente doctrina alemana contemporánea, ejemplificada en nombres como, entre otros, los de Hesse, Stern, Müller o Häberle ${ }^{55}$.

En polémica con la afirmación de Jellinek de que las fuerzas políticas reales se mueven según leyes propias que operan independientemente de todas las formas jurídicas ${ }^{56}$, Smend presenta una (llamada) "teoría de la integración", que intenta demostrar el influjo recíproco entre fuerza real y forma jurídica ${ }^{57}$. Si Kelsen representa la apoteosis del Derecho y del Estado, identificados en la lógica trascendente de los hechos sociales, Smend reconstruye los conceptos de Estado y Constitución, sobre la base de los procesos vitalizadores e integradores que subyacen en ambos. A Kelsen se le escapa la realidad social incrustada en el Derecho, pero Smend descuida la capacidad normativizadora que tiene el Derecho para disciplinar la realidad social ${ }^{58}$.

El antipositivismo de Smend arranca de su propia concepción del Estado. Para él el Estado no es la mera asociación de todos aquellos que jurídicamente pertenecen al mismo, no "un fenómeno natural que deba ser simplemente constatado”, sino

\footnotetext{
55 Cfr. Pablo Lucas Verdú, La lucha contra el positivismo jurídico en la República de Weimar..., cit. nota 99, pp.141-142.

56 Cfr. Georg Jellinek, Reforma y mutación de la Constitución, Madrid, Centro de Estudios Constitucionales, 1991, p.6: “El legislador se enfrenta con poderes que se cree llamado a dominar pero frecuentemente se alzan, plenamente inadvertidos, contra él atreviéndose incluso a sustituirle. Tales poderes no se arredran de ninguna manera ante las leyes más elevadas y profundas (...)".

57 Ulderico Pomarici, "La teoria dell'integrazione in Rudolf Smend", Democrazia e Diritto, XXII (1982), pp. 119 y ss.; cfr. también el punto de vista (sumamente crítico para con el autor alemán, por las concomitancias de la teoría de la integración con la literatura del fascismo) de Massimo La Torre, en "Patologías del comunitarismo. Rudolf Smend y la teoría de la integración", Ponencia presentada al Simposio Literatura y política en la época de Weimar, organizado por la Universidad de Salamanca y celebrado en dicha ciudad del 9 al 11 de abril de 1997.

58 Pablo Lucas Verdú, La lucha contra el positivismo, cit. nota 99, pp. 175-176.
} 
"una realización cultural que, como tal realidad de la vida del espíritu, es fluida, necesitada continuamente de renovación y desarrollo" 59 . La integración se presenta así como el proceso fundamental de la dinámica del Estado:

"El objeto de la teoría del Estado y del derecho constitucional es el Estado en cuanto parte de la realidad espiritual. Al ser partes de la realidad, las formas espirituales colectivas no constituyen sustancias estáticas, sino una unidad de sentido de realidad espiritual, esto es, actos espirituales. Lo que les caracteriza es un proceso de actualización funcional, de reproducción; dicho con más precisión, un continuo proceso de laboriosa configuración social (...). Únicamente en y a través de este proceso existen, o mejor, son realizadas nuevamente en cada instante aquellas formas colectivas" ${ }^{60}$.

La Constitución, por su parte, "es la ordenación jurídica del Estado, mejor dicho, de la dinámica vital en la que se desarrolla la vida del Estado, es decir, de su proceso de integración" ${ }^{61}$. Esta integración es tanto de carácter real, como personal y funcional. Smend presenta, pues, a la Constitución no sólo como una norma, sino como realidad, como "realidad integradora" $\mathrm{o}$, lo que es lo mismo, como ética constitucional. La Constitución es disciplina jurídica (del proceso de integración) y, al mismo tiempo, realidad integradora, en la medida en que produce, por sí misma, integración.

"Lo que distingue a esta teoría de la Constitución de las teorías al uso - prosigue Smend, para resaltar la originalidad de su contribución - es que responde a un planteamiento de las ciencias del espíritu. Es lógico, por tanto, que se rechacen todas aquellas teorías que ven en la Constitución un aparato técnico y objetivo que actúa de forma mecánica (...). La teoría tampoco es compatible con una sustantivación de la Constitución que pretenda

\footnotetext{
59 Rudolf Smend, Constitución y Derecho Constitucional, cit. nota 94, p. 61.

60 Constitución y Derecho Constitucional, p. 62.

61 Constitución y Derecho Constitucional, p. 132.
} 
identificar Estado y Derecho, basándose en un prurito realista que, en el mejor de los casos, pertenece a épocas arcaicas" ${ }^{\prime 2}$.

Las distancias también aparecen marcadas, y con especial énfasis, con respecto a la teoría de la Constitución como supernorma:

"(...) la naturaleza de la Constitución exige la toma en consideración de un objeto y una función constitucionales específicas (...). E implica, ante todo, el rechazo de la pretensión normológica de articular la Constitución como parte integrante e incluso como requisito imprescindible para la validez de cualquier ordenamiento jurídico. Esta concepción atacaría directamente el concepto propio de Constitución y, más aún, la dignidad de todo Derecho y de toda idea de Derecho"63.

Pero lo más interesante, a nuestro juicio, de la aportación de Smend es el haber defendido que la interpretación constitucional exige una técnica peculiar y diferenciada de la utilizada en los restantes sectores del ordenamiento. Las Constituciones, dice Smend, "contienen disposiciones normativas cuya función estriba justamente en contraponer una sólida y firme barrera frente a las fuerzas sociales en perpetua ebullición". Eso ocurre especialmente con los derechos fundamentales de la persona, con la positivización de normas generales de carácter supraestatal y con el reconocimiento de los derechos de las minorías frente a la naturaleza unificadora del Estado, si bien -añade sorprendentemente Smend, revelando una concepción que hoy nadie compartiría - "esto no sucede con algunas Constituciones, sobre todo en Estados democratizados". En todo caso, concluye:

"Por su propia naturaleza la Constitución no tiende, así pues, a regular supuestos concretos, sino a abarcar la totalidad del Estado y la totalidad del proceso integrador. $Y$ es esta misma finalidad la que no sólo permite, sino que incluso exige del intérprete constitucional una interpretación extensiva y

\footnotetext{
62 Constitución y Derecho Constitucional, pp. 141-142.

63 Constitución y Derecho Constitucional, p. 135.
} 
flexible, que difiere en gran medida de cualquier otra forma de interpretación jurídica" ${ }^{64}$.

Estamos, en suma, ante una teoría cuyo esfuerzo por salvar al Derecho Constitucional, y al derecho tout court, de su identificación con el poder, resulta notable. Pero se trata, al mismo tiempo, de una teoría cuyo sociologismo la hace en exceso evanescente y falta de concreción. Su problema es, quizá, el que corresponde al momento en el que fue publicada (1928): la obsesión por poner a resguardo la unidad del Estado en la época inaugural de un pluralismo disolvente y potencialmente destructivo. Desde sus profundas convicciones religiosas, el legado de Smend bien puede concretarse en su insistencia en las peculiaridades del Derecho Constitucional como derecho de la integración; un derecho, según él, más sugerente que coactivo, ante la ausencia (por entonces) de una instancia heterónoma capaz de suscitar acatamiento ${ }^{65}$.

Herman Heller (1891-1933) culmina la pléyade de autores del período weimeriano con una obra que aspira a superar, de una vez por todas, la escisión entre realidad social y orden jurídico, construyendo un concepto de Constitución que sirva como síntesis de ambos. Su contribución ha sido presentada como el mejor producto del pensamiento jurídico-político de la época, así como "la más sólida cimentación del modelo paradigmático de Constitución que se generalizará tras la caída de los fascismos europeos" ${ }^{66}$.

El decisionismo y el normativismo avalorativo, pese a las diferencias que los separan, según hemos apuntado, son teorías que expulsan de su seno cualquier elemento de racionalidad y objetividad referido a los contenidos del propio Derecho, con

\footnotetext{
64 Constitución y Derecho Constitucional, p. 133.

65 Cfr. la Introducción de Gustavo Zagrebelsky a la traducción italiana de Constitución y Derecho Constitucional (Milán, Giuffré, 1988), así como las citadas obras de Lucas Verdú, La lucha contra el positivismo..., especialmente, Cpt. II ("Rudolf Smend y la República de Weimar") y Massimo La Torre ("Patologías del comunitarismo...").

66 Mario Dogliani, Introduzione al Diritto Costituzionale, cit., p. 297.
} 
lo que la función de éste, con respecto a las características de la sociedad en la que actúa, es algo que escapa por completo a las preocupaciones de tales teorías. La teoría de la integración, de Smend, es un primer filón a través del cual la teoría constitucional intenta resucitar el nexo entre sociedad civil y poder político, propio de la gran tradición iusnaturalista que alumbró al Estado constitucional en sus primeros pasos. Pero se trata todavía de un filón angosto, puesto que, una vez descrita la Constitución como disciplina del proceso de la integración, en absoluto se abandona el agnosticismo con respecto a los contenidos, los medios y los objetivos de dicha integración.

Heller abre de lleno la voluntad creadora de Derecho al influjo de principios jurídicos generales de contenido ético, que se erigen en presupuesto de la positividad del Derecho. Como dice Niemeyer, prologuista de la edición española de la obra capital de Heller, la Teoría del Estado, publicada con carácter póstumo en 1934, "de la misma manera que el que quiera hacerse entender ha de observar las reglas del lenguaje, quien aspire a mandar con carácter de permanencia, es decir, por las vías del derecho, ha de hacerlo dentro de los contenidos jurídicos conocidos por los destinatarios de la norma, o sea por medio de una decisión sometida a los principios jurídicos válidos en el grupo social" ${ }^{67}$.

Así pues, en Heller encontramos un rechazo frontal de la escisión irreductible entre el sein y el sollen, característica del pensamiento de Kelsen. El deber ser no es para él una categoría lógica, desconectada de la realidad, y racionalmente inaprensible, sino valor y exigencia ética que acompaña y se dirige a una conducta humana. "El problema del Estado y del Derecho - dirá Heller - es el de la unión de voluntad y norma, del ser con el deber ser" ${ }^{\prime 68}$.

67 Gerhart Niemeyer, "Prólogo" a Herman Heller, Teoría del Estado, Méjico, Fondo de Cultura Económica, 1942, p. 14.

68 Herman Séller, Die Souveränität, p. 77; cfr. Enrique Gómez Arboleya, "Herman Heller", en Estudios de teoría de la sociedad y del Estado, cit., pp.15 y ss. 
Heller defiende de manera resuelta la dignidad científica del sincretismo epistemológico: "puesto que el objeto de las ciencias del espíritu es en conjunto algo que viene dado (...), puede ser comprendido sólo gracias a un sincretismo metodológico. El imperialismo de un único método se muestra estéril en todas las ciencias del espíritu". Y también: "Todo problema jurídico, sin excluir ninguno, radica, por debajo, en la sociología, y en lo alto en la esfera ético-política, y no es únicamente accesible a un análisis causal o a uno normativo, sino que requiere los dos"69. Unas observaciones en todo coincidentes a las realizadas por Triepel, en 1926, con ocasión de su célebre discurso de toma de posesión como rector de la Universidad de Berlín:

"El que se pueda estudiar el Derecho público con tal exclusividad metódica -ironiza Triepel refiriéndose expresamente a Gerber, Laband y Kelsen - no ofrece duda. Sin embargo a costa, en último término, de un empobrecimiento de nuestra ciencia, que debe pagar verdaderamente cara la gloria de la pureza metódica. (...) El sincretismo metódico no es ningún crimen de lesa majestad (...). Las reglas del deber ser jurídico son siempre la expresión de valoraciones universales y se refieren según su sentido a objetos que han sido pensados como medio de realización de determinadas finalidades. Por consiguiente, uno no puede llegar de ningún modo a un conocimiento de las normas jurídicas sin formarse una idea de las relaciones finalistas de las que trata lo jurídico, de los intereses cuyo reconocimiento, desaprobación o coordinación constituye la primera tarea o -si se quiere- la condición previa del ordenamiento jurídico"70.

El adversario científico de Heller no será, pues, Jellinek, el autor de la gran obra por entonces de referencia, con su tesis "de las dos orillas" para la aproximación al fenómeno estatal, sino el coetáneo del primero, Kelsen, quien había llevado hasta

69 H. Heller, La sovranità ed altri scritti sulla dottrina del diritto e dello Stato, Milán, Giuffrè, 1987, passim; cfr. Massimo La Torre, "Un jurista en el crepúsculo de Weimar. Política y Derecho en la obra de Herman Heller", cit., p.26.

70 Heinrich Triepel, Derecho público y política, Madrid, Cívitas, 1974, pp.50-53. 
las últimas consecuencias la obsesión por la pureza metódica. La crítica fundamental que dirige a éste, y a su reine Staatslebre, es la de ser "una teoría del Estado sin Estado".

Heller conecta el orden social con el Estado, entendido como organización, como forma social, con su doble carácter: histórico (el Estado es vida en decurso y movimiento, "vida en forma y forma que surge de la vida") y cultural (la teoría del Estado es ciencia de la estructura de una determinada formación, la del Estado occidental de la era moderna). El paso que le interesa es el que lleva desde la "uniformidad del comportamiento social a la unidad de la acción colectiva", un paso que se lleva a cabo mediante la actuación de los órganos del Estado:

"La tensión entre ser y deber ser no debe resolverse nunca unilateralmente, ni en favor de lo normativo, ni del lado de la realidad social (...). El establecimiento y aseguramiento de las reglas convencionales, v. gr. las normas de la decencia y urbanidad, resultan de la aceptación o reprobación de la opinión pública no organizada. En cambio el ordenamiento jurídico tiene a su disposición una organización especial a cuyos órganos incumbe la tarea específica de garantizar el nacimiento y mantenimiento del derecho" $"$.

Lo que Heller se plantea entonces es la cuestión de la finalidad de tal organización especial, dicha Estado, cuyos órganos crean y mantienen el derecho ("La determinación de la función de sentido, inmanente, del Estado es de importancia decisiva para la comprensión del mismo en todos sus detalles. Sin una referencia a la función de sentido del Estado, todos los conceptos de la teoría del Estado y del Derecho Político aparecen vacíos de significado") $)^{72}$.

En polémica con las corrientes irracionalistas a la hora de buscar fundamento al ejercicio del poder político (Sorel, Pareto, Spengler y, en especial, Schmitt), Heller acoge la justificación moral:

71 Heller, Teoría del Estado, p. 203.

72 Teoría del Estado, p. 221. 
"La función de sentido del Estado, como la de todo fenómeno histórico, siempre está, ciertamente, referida a valores. Pero esta relación puede ser positiva o negativa. Cualquier banda de ladrones u organización de asesinos tiene también un sentido comprensible. La cuestión de la consagración o justificación del Estado no puede, pues, resolverse con la simple consideración de su función comprensible"73.

Tal es el punto crucial de la aportación de Heller. El poder del Estado alberga la pretensión de vincular, en tanto que autoridad legítima, las conciencias, también éticamente ("Al demostrar que, históricamente, ha prevalecido siempre el derecho del más fuerte, se cree haber demostrado también que siempre debe ser así (...). Olvídase que sólo existe una historia específica del hombre o de la cultura debido a que el hombre es esencialmente 'utópico', es decir, porque es capaz de contraponer al ser un deber ser y valorar el poder actual según una idea del derecho") ${ }^{74}$. El Estado no vale entonces porque asegure la vigencia de un orden social cualquiera en un territorio, sino por la aspiración a realizar un orden justo. Así como el Estado sólo puede ser comprendido a partir de la realidad social, así también su legitimación únicamente puede provenir de "una realidad aprobada por la conciencia ética", y sobre la base "de un criterio jurídico situado por encima del Estado y de su derecho positivo":

"En una Teoría del Estado que tenga carácter de ciencia de la realidad hay que dar por admitido (...) que existen tales principios éticos del derecho que forman la base de justificación del Estado y del derecho positivo" 75 .

Estos principios, prosigue Heller, apoyándose en el artículo 38 de los Estatutos del Tribunal de la Haya con su mención a les principes généraux de droit reconnus par les nations civilisées,

73 Teoría del Estado, p. 234.

74 Teoría del Estado, pp. 238-239.

75 Teoría del Estado, p. 242. 
"constituyen el fundamento normativo no sólo del derecho estatal, sino también del derecho interestatal", y "proporcionan sólo las directrices generales sobre cuya base debe establecerse el status jurídico entre los miembros de la comunidad jurídica".

El hipotético conflicto entre los preceptos positivos y los deberes impuestos por principios éticos del derecho, le da pie a Heller para embarcarse en interesantes consideraciones sobre la seguridad jurídica, la razón de Estado y la razón de derecho ("Una bien entendida razón de Estado, no requiere (...), en modo alguno, la capitulación de la conciencia jurídica, y la admisión de un derecho de resistencia de carácter ético no nos lleva tampoco a la anarquía") ${ }^{76}$.

Como señala Massimo La Torre, se podría decir que el modelo del último Heller recuerda la construcción de Robert Alexy del derecho a dos niveles, un Regel/Prinzipien Model que aleja al sistema tanto de cualquier concepción angostamente iuspositivista, como de una de tipo decisionista ${ }^{77}$. Conforme a dicho modelo, el sistema jurídico no consiste sólo en leyes, decretos o mandatos del soberano, sino que está colmado de otros aspectos, de principios, sobre todo. Estos, por su naturaleza, no pueden ser reducidos a elementos de una realidad meramente empírica, fáctica, sino que desempeñan una función de regulación ideal de la conducta, que remite a una actividad de ponderación entre alternativas distintas, realizable mediante el recurso a argumentos de racionalidad práctica.

"Sin esa apelación a los principios jurídicos, - dirá Heller al glosar uno de los conceptos de Constitución por él construido incluso en los casos en que el legislador no se remite expresamente a ellos, no se pueden comprender ni interpretar ni aplicar la mayoría de los preceptos positivos del derecho Constitucional. Pues nunca está comprendido todo el derecho en la letra de los preceptos jurídicos positivos" ${ }^{78}$.

\footnotetext{
76 Teoría del Estado, pp. 244-245.

77 Massimo La Torre, "Un jurista en el crepúsculo de Weimar...", cit.

78 Teoría del Estado, p.276.
} 
Ahí radica el verdadero genio de Heller, un iuspublicista precursor en muchos de sus planteamientos - a él se debe la fórmula "Estado social", hoy indiscutida - y del que Lucas Verdú afirma, con toda razón, que, a diferencia de Schmitt, "si hubiera vivido, hubiera sido un vencedor convencido", así como que "sus ulteriores enseñanzas habrían contribuido (...) a iluminar la marcha y futuro del ius publicum europeum" "79.

De menor interés nos parece, en cambio, la contribución de Heller relativa al concepto o, por mejor decir, a los conceptos, de Constitución. Como es sabido, Heller proporciona hasta cinco conceptos de Constitución: dos sociológicos, dos jurídico-materiales, y uno jurídico-formal ${ }^{80}$.

Los conceptos sociológicos se refieren a la Constitución como realidad social no regulada por normas (sociológico en sentido amplio), y a la Constitución como realidad social regida por normas extrajurídicas y jurídicas (sociológico en sentido estricto). A estos conceptos sociológicos se agregan, en perfecta simetría, otros tantos conceptos jurídico-materiales, que vienen a dar cuenta de la autonomía cobrada por las constituciones en el proceso de la experiencia histórica. El primero de ellos hace de la Constitución algo más o menos equivalente al concepto de ordenamiento jurídico (el conjunto de las normas del Estado); el segundo, más reducido, se refiere sólo a aquella parte del ordenamiento considerada como esencial, por ejemplo, la que asegura ciertos derechos individuales y la división de los poderes del Estado. Junto a estos dos conceptos jurídicomateriales, el elenco termina con un concepto jurídico-formal (la Constitución registrada en un documento escrito, en la que se incluye aquella parte del ordenamiento considerada como esencial). Heller reitera aquí las referencias a Lassalle ("en último extremo siempre se mantiene la verdad de la proposición de que la constitución efectiva reside en las relaciones objetivas de poder"), si bien constata "la tendencia a armonizar,

79 Pablo Lucas Verdú, Curso de Derecho Político, Madrid, Tecnos, 1976, vol. I, p. 92.

80 Herman Heller, Teoría del Estado, Cpt. III. 5 (“La Constitución del Estado”, passim) 
hasta donde sea posible, el texto constitucional escrito con la Constitución material en sentido estricto", una tendencia que hace científicamente necesario el concepto de Constitución formal, "porque nunca puede darse una correspondencia perfecta entre la Constitución material y la formal".

Detengámonos en esta última contraposición, con la que Heller culmina su empeño de esclarecimiento conceptual.

La expresión Constitución material es, como se ha dicho, una "fórmula multiuso para expresar la idea de super-constitución" $"$. Asentada sobre la constatación, bastante obvia, de que una Constitución no resulta comprensible si se la deslinda del específico contexto socio-temporal en el que aspira a regir, ha dado lugar a un sinfín de formulaciones cuyo denominador común es el intento de socavar los ideales del constitucionalismo, plasmados en el concepto liberal/revolucionario de Constitución. Con variantes muy distintas (el historicismo reaccionario, el sociologismo de impronta socialdemócrata, el decisionismo schmittiano, las tesis de un Smend o un Heller, recién recogidas, y el ordinamentalismo de Santi Romano), la idea es llevada a su más acabada expresión por un autor italiano, cuyo influjo, en el país transalpino, y entre nosotros, nunca ha dejado de sorprenderme.

Me refiero, claro está, a Costantino Mortati, y a su obra La Costituzione in senso materiale, publicada en 1940 (el "año XVIII del fascismo”, según consta en la primera edición). La Constitución material aparece allí definida como la "fuerza resultante de la organización de un grupo social que se singulariza de los demás y que logra, triunfando sobre grupos antagónicos y portadores de intereses diversos, hacer valer efectivamente la forma particular de orden por él afirmado" ${ }^{2}$. En la edición

\footnotetext{
81 Antonino Spadaro, Contributo per una teoria della Costituzione. Fra democrazia relativista e assolutismo etico, Milán, Giuffrè, 1994, p. 23.

82 Cfr. Javier Jiménez Campo, "Contra la Constitución material", en Estudios de Derecho Público en homenaje a Juan José Ruiz-Rico, Madrid, Tecnos, 1987, vol. I, pp. 42 y ss.
} 
posterior, aparecida ya en vigor la nueva Constitución republicana, la definición se matiza y se transforma en "organización de las fuerzas sociales establemente ordenadas en torno a un sistema de intereses y fines determinados". Algo, como se ve, que difícilmente podría ser menos preciso en sus postulados, pero cuya potencialidad disolvente de la normatividad constitucional tampoco es desdeñable. Abandonada la constitución formal a su suerte sociológica, despojada de su pretensión reguladora, y degradada en rango frente a la constitución efectiva, que se hace equivaler, en nombre del realismo político, a las orientaciones (indirizzi) triunfantes, aquélla queda deslegitimada e inerme, si llega el caso de su quiebra.

Estamos ante una construcción que desatiende lo que la Constitución tiene de documento prospectivo, de proyecto conformador de una realidad política, una construcción que despoja a la Constitución de las notas, consustanciales a toda orden jurídica, de objetividad, normatividad y certeza. La Constitución en sentido material viene a culminar lo que había sido una constante del pensamiento jurídico desde que éste recibió el impacto de los saberes sociológicos, en una operación de búsqueda de los fundamentos reales del derecho, que el iusnaturalismo racionalista o el romanticismo de la Escuela histórica ya no proporcionaban.

La denuncia de los factores ideales inscritos en la ciencia del derecho trajo consigo una glorificación de lo subjetivo, con afirmaciones del tipo "la positividad del derecho descansa siempre, en último extremo, en el convencimiento de su validez existente en la mayoría del pueblo". Tal es lo que Max Weber llamaría el fundamento de la validez empírica o sociológica del derecho ("la probabilidad por término medio de que los afectados por la disposición impuesta la consideren de hecho como válida para su comportamiento"), en contraste con la validez ideal, la del deber ser de la orden jurídica ${ }^{83}$.

83 Max Weber, Economía y Sociedad, Méjico, Fondo de Cultura Económica, 1964, p. 253. 
Indicar, como hizo Heller, que "la cúspide de la organización significa siempre el límite del aseguramiento coactivo organizado por el derecho" ${ }^{84}$, supone reproducir la aporía de los límites del poder supremo, pero se trata de algo que en absoluto afecta exclusivamente a la Constitución en tanto que cúspide. Cualquier norma, sea del rango que sea, es tributaria de la voluntad social de mantenerla viva.

Una constatación tan simple como la recién expuesta es el punto de partida de las teorías del reconocimiento, en sus diversas formulaciones; así, la preconizada por Adolf Merkel, quien habla de la "alianza de las prescripciones jurídicas con las fuerzas morales vivas de un pueblo", para circunscribir el reconocimiento a los principios jurídicos fundamentales y no a todas y cada una de las reglas del sistema (teoría del reconocimiento general). El propio Merkel se refiere a las "estaciones de conexión", imprescindibles para pasar desde la validez sociológica a la jurídica. Esas "estaciones de conexión" son los tribunales, "instrumentos de la vigencia del espíritu de la época" ${ }^{85}$.

La teoría del reconocimiento recibirá sucesivas formulaciones de la mano de la filosofía analítica de Hart, o a partir de planteamientos más actuales, como el de la "moral institucional", a los que más abajo nos referiremos. En todo caso, desde el grado de desarrollo alcanzado por el Derecho Constitucional hasta nuestros días, baste por ahora con señalar la inconsistencia de las tesis de la Constitución material. Como dice Jiménez Campo, "no Constitución formal frente a Constitución material, sino escuetamente Constitución, que es configuración de la realidad". Y concluye:

"Constitución con ambición de realizarse, porque en ella está - o debería estar - la autoconciencia histórica de un pueblo

\footnotetext{
84 Teoría del Estado, p. 288.

85 Cfr. Hans Welzel, “El problema de la validez del Derecho (una cuestión límite del Derecho)", en Derecho injusto y Derecho nulo, Madrid, Aguilar, 1961, pp. 72 y ss.
} 
y, por lo mismo, la expresión sintética de esa filosofía práctica que fue siempre, ya en sus orígenes, el constitucionalismo, la filosofía que quiso dar forma al deseo y a la voluntad de guiar racionalmente la propia historia" ${ }^{\prime 6}$.

${ }^{86}$ Javier Jiménez Campo, "Contra la Constitución material", cit., p. 54. 